\title{
Pseudopelade of Brocq
}

INSERM

\section{Source}

INSERM. (1999). Orphanet: an online rare disease and orphan drug data base.

Pseudopelade of Brocq. ORPHA:129

Pseudo-pelade of Brocq is a rare hair abnormality characterized by onset in adulthood of soft, irregular, flesh-toned patches of alopecia primarily in the parietal and vertex portions of the scalp, without follicular hyperkeratosis or perifollicular inflammation. 